\title{
An Innovative Approach for Energy Generation from Waves
}

\author{
A. Al-Habaibeh, D. Su \\ Advanced Design and Manufacturing Engineering Centre, Nottingham Trent University, UK \\ J. McCague, A. Knight \\ Ocean Navitas Ltd, Lincolnshire, UK
}

\begin{abstract}
Sustainable Energy Generation is becoming extremely imperative due to the expected limitations in current energy resources and to reduce pollution. Wave energy generation has seen significant development in recent years. This paper describes an innovative system for generating energy from wave power. A complete description of the system is presented including the general concept, configurations, mechanical design, electrical system, simulation techniques and expected power output of the system. This presented work has been developed as a collaborative work between Nottingham Trent University and Ocean Navitas Ltd. The results show that this new technology could provide an efficient and low cost method of generating electricity from waves.
\end{abstract}

\section{INTRODUCTION}

Utilisation of renewable energy is becoming essential to sustain people's lifestyle, reduce carbon emissions of greenhouse gases and lessen the consumption of limited resources. The current global economic uncertainties and the fluctuation of energy prices are forcing countries and organisations to research and develop more efficient green energy generation methods. Recently, gas supplies for several European countries were disturbed as a result of a commercial disagreement [1] and many countries are working towards more independence in relation to their energy supplies. In the UK, the Government aims, based on Kyoto protocol, to produce $10 \%$ of power needs from renewable sources by 2010 , and aspires to produce $20 \%$ by 2020.

Renewable energy, including solar energy, wind energy, wave energy, tidal energy geothermal, hydropower, biomass and biofuels, is energy generated from natural resources that are naturally replenished. More research has been done in recent years in relation to renewable energy, see for example [2-5]. Each source of energy has its own advantages and disadvantages. For example, biofuel uses the energy contained in organic crops such as sugarcane and corn to produce ethanol, an alternative to fossil-based fuels such as petrol. This has made farmers around the world to focus on fuel crops in order to increase their profit which resulted in a relative increase in food prices in 2008 [6] and growing international criticism of the production of biofuel crops in association with food crops with respect food security

This has given focus on more suitable biofuel products such as the utilisation of algae which also can consume $\mathrm{CO}_{2}$ emission and produce $\mathrm{O}_{2}$ [7]. Wind power energy generation is becoming a well-established technology. However, wind power is unpredictable and Energy suppliers use it most of the time as a 'top up' source of power. Moreover, campaigners in the countryside object to the technology and claim that it damages the natural beauty and produces significant noise. Geothermal and hydropower are technologies limited to specific geographical locations.
Wave energy generation is not widely employed due to several technical challenges since waves move at lowspeed with high forces combined with multi-dimensional and complex motion. Moreover, most commercial electric generators operate at higher speeds and would require steady-state conditions

This paper will describe the innovative technology that has been recently developed by Ocean Navitas Ltd with collaboration from Nottingham Trent University to overcome the technical challenges to produce clean and sustainable energy from waves at very competitive prices

\section{WAVE ENERGY GENERATION}

Wave energy generation refers to the energy of ocean surface waves and the utilisation of that energy to generate electricity. Wave energy depends on wind speed, time duration of the wind blowing, the distance of open water that the wind has blown over (fetch), and water depth [8]. Wave power could be determined by wave height, wavelength, and water density. This mathematically could be described as in equation (1) [9]

$$
P=\frac{\rho g}{64 \pi} H^{2} T \approx \frac{1}{2} H^{2} T \quad \mathrm{~kW} / \mathrm{m} \quad \mathrm{Eq}(1)
$$

where:

$P$ : wave energy flux per unit wave crest length $(\mathrm{kW} / \mathrm{m})$

$\rho:$ the mass density of the water $\left(\mathrm{kg} / \mathrm{m}^{3}\right)$,

$g$ : gravitational gravity $\left(\mathrm{m} / \mathrm{s}^{2}\right)$

$H:$ Wave height (m)

$T$ : Wave time cycle (s)

For example: for a $1.6 \mathrm{~m}$ wave and 10 seconds period, the power produced is approximately $12.8 \mathrm{~kW} / \mathrm{m}$.

\subsection{Recent Technologies in Wave energy}

Recent years have seen several developments in energy generation from waves. Oscillating water column wave energy converter (OWC) [10] is a method that depends on the air column and the deference in pressure generated from waves as in Figure 1 


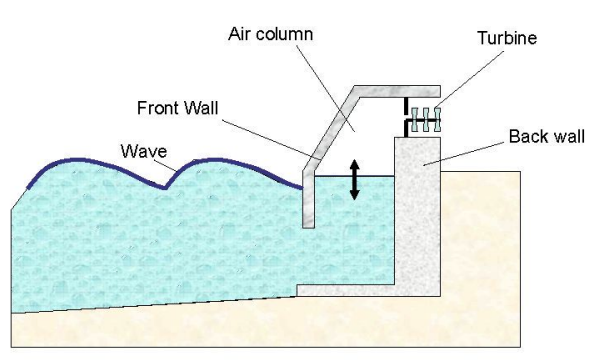

Figure 1: A schematic diagram of an Oscillating Water Column wave energy converter (OWC).

It is similar to a wind turbine which depends on the change of water height due to the wave to generate air pressure. A chamber is placed above the water and the movement of waves changes the water level within the housing causing change in air pressure and air flow Because of the bidirectional air flow during the wave cycle, the turbine is designed to rotate in only one direction to utilise the energy from full cycle of wave. The disadvantage of this method is that it has low efficiency since it is a shoreline device and requires significant fixed structures. Moreover, the tidal waves may cause problems for a fixedly moored OWC.

The world's first commercial wave farm was developed in the UK and installed in Portugal [11] at the Aguçadora Wave Park, which consists of three 750 kilowatt Pelamis Wave Energy Converter devices. The sections of the device articulate with the movement of the waves, the energy from the relative motion between the sections forces a pressurised oil to drive a hydraulic ram which drives a hydraulic motor. The machine is long and narrow (snake-like) and points into the waves. Its articulating sections drive internal hydraulic generators by the utilisation of pumps and accumulators. Figure 2 presents a schematic diagram of the Pelamis system.

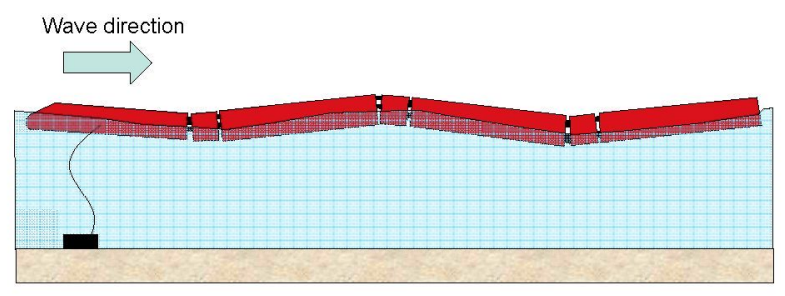

Figure 2: A schematic diagram of a Pelamis Wave Energy Converter

The disadvantage of this system is expected to be in the massive size of the device where the diameter is about 3 metres and length of 4 sections is about 150 metres [12].

Another configuration for wave energy generation is shown in Figure 3. The overtopping wave energy converter [13] works in much the same way as a hydroelectric dam. Waves roll into a collector which funnels the water into a hydro turbine. The turbines are connected to generators which produce electricity. After the waves flow through the turbines they move back to the ocean.

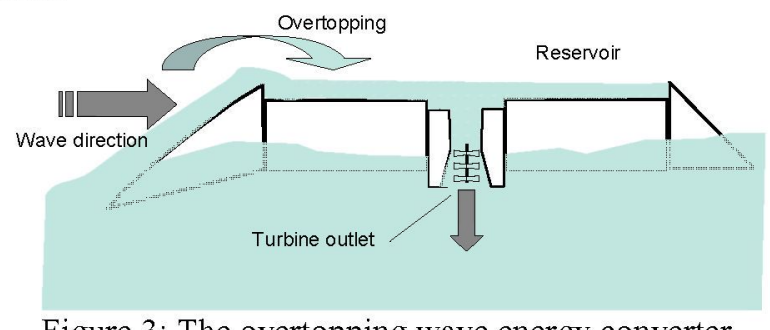

Figure 3: The overtopping wave energy converter

Several other methods have been described in literature that utilise the rising and fall of the waves' movement via a floating buoy-like structure creating mechanical energy which is converted into electricity and transmitted to shore over a submerged transmission line. This is done through compressing sea water $[15,16]$ or through linear electric generators [17].

Many of the existing technology seems overly complex and uses energy conversion techniques that by their nature require large, expensive devices with a poor mass to power output ratio, and in most cases they are difficult to be scaled down or used off-shore and on shorelines.

\subsection{Ocean Navitas Technology}

Ocean Navitas' technology is called The Aegir Dynamo $^{\mathrm{TM}}$. The name is derived from the name for the Norse god of the sea 'Egir' and the dynamo is 'an electrical generator'. The Aegir Dynamo ${ }^{\mathrm{TM}}$ functions in a unique fashion by generating electrical current from the motion of the prime mover in one phase via a direct mechanical conversion and the use of a bespoke buoyancy vessel. As shown in Figure 4, the principle is relatively simple; an Aegir Dynamo is housed in a sealed central column which remains in a relatively stationary position due to ballast and the moored reactor plate at its base. The Buoyancy float moves up and down due to its reaction to the change in water level and the effect of gravity. The motion of the buoyancy float is transferred to the Aegir Dynamo by a shaft. The Aegir Dynamo converts both the upward motion of the waves and the downward motion of gravity into singular direction rotational energy at an estimated efficiency of about $96.5 \%$. This rotational energy is then transferred to a standard permanent magnet alternator as developed for the wind turbine energy. The result is clean, predictable and reliable electricity at a calculated cost competitive with traditional fossil fuels when deployed in arrays or 'sea farms'. The Aegir Dynamo is also designed to be modular allowing several units to be installed in the same device. This effectively means that the technology can be stepped up in rated power output without significant losses in efficiency or increases in size. The technology has been designed for deployment in two formats, one for off-grid shore-based applications to service isolated coastal communities, and one for offshore buoy formats to generate commercial levels of electrical 
energy in farms. Figure 5 represents an example of using several devices in a sea farm for power generation.

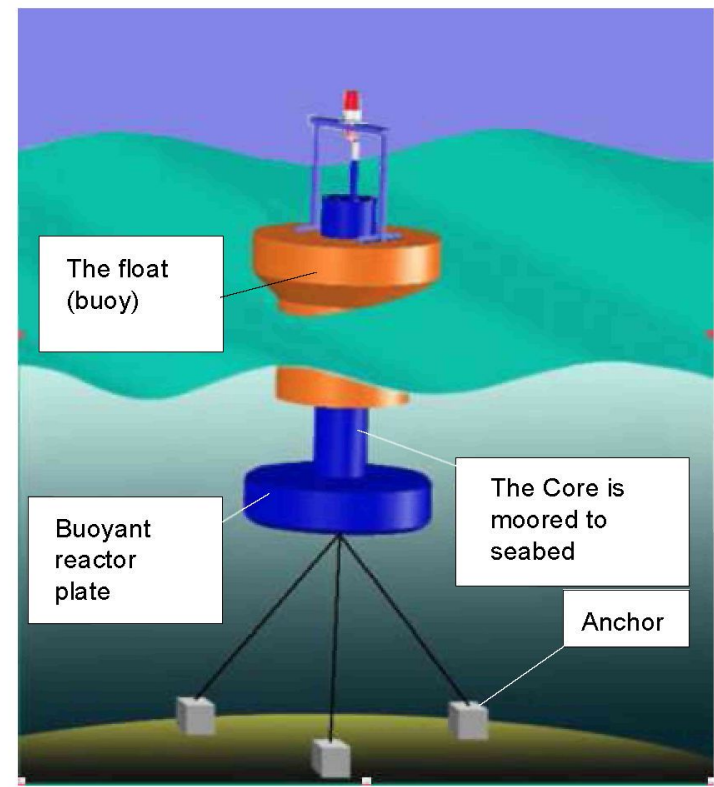

Figure 4: A simplified schematic of Ocean Navitas technology.

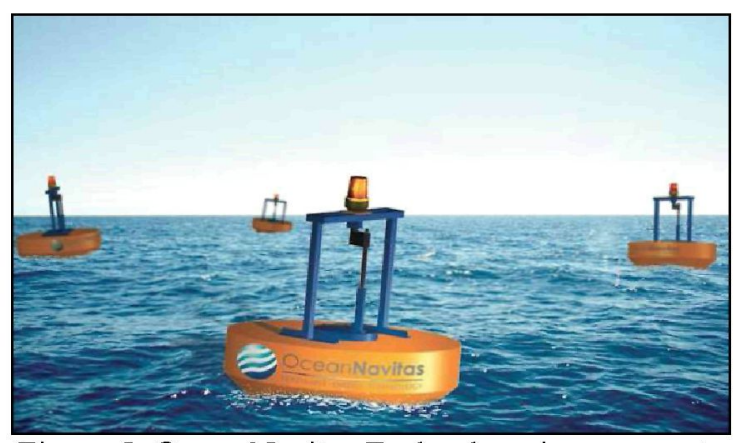

Figure 5: Ocean Navitas Technology in an array to produce energy at commercial scale.

To validate this concept a $2 \mathrm{~kW}$ Aegir Dynamo prototype has been developed including the Aegir Dynamo energy conversion device.

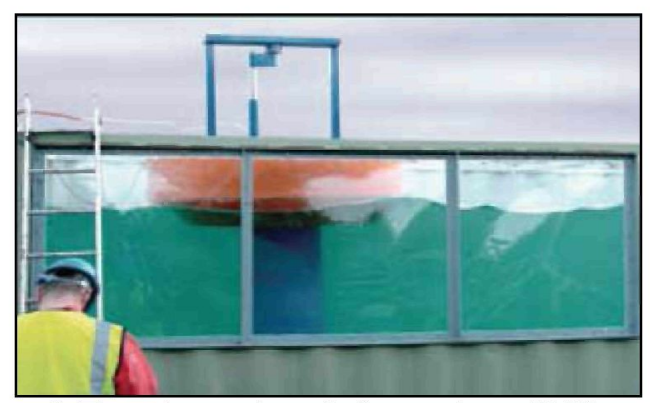

Figure 6: Experimental work for testing a $2 \mathrm{~kW}$ system.

The system is experimentally tested as shown in Figure 6 to evaluate the suitability of the technology for different wave heights and time periods. Computer models and extrapolation calculations have predicted that this device, when scaled up to a $1.4 \mathrm{MW}$ output, will produce electricity at a cost comparable with conventional coal fired power generation if installed in a suitable location. This means it has the potential to be more efficient than not only existing wave power technology, but also wind turbines and fossil-fuel generators.

The positive impact of the Aegir Dynamo on greenhouse gas emissions is expected to be significant. The latest available figure from The Carbon Trust (UK) for grid electricity is $0.43 \mathrm{~kg}$ of carbon per $\mathrm{kW}$ of electricity generated. As the Aegir Dynamo generates electricity from renewable, carbon free means, it can be calculated that a single $1.4 \mathrm{MW}$ device has the potential to save 3766 tones of carbon emissions that are currently being released into the atmosphere in a single year when using fossil-fuel. If Ocean Navitas can place as little as 20 Aegir Dynamo devices around the coast of the UK by 2010 this will reduce carbon emissions by a staggering 75000 tones per year.

The success of the $2 \mathrm{~kW}$ system has lead into the design of an affixed $45 \mathrm{~kW}$ shore-based device to service small coastal and island communities, expressly those who use fossil fuelled generators. Scaled a 4.5 meters across the accelerator flume it has been calculated that the shore based Aegir Dynamo will produce $45 \mathrm{~kW}$ of electricity at less cost than a wind turbine of a similar capacity. The shore based Aegir Dynamo can be situated on marina walls, key-sides and any fixed structure that is serviced by waves, as presented in Figure 7.

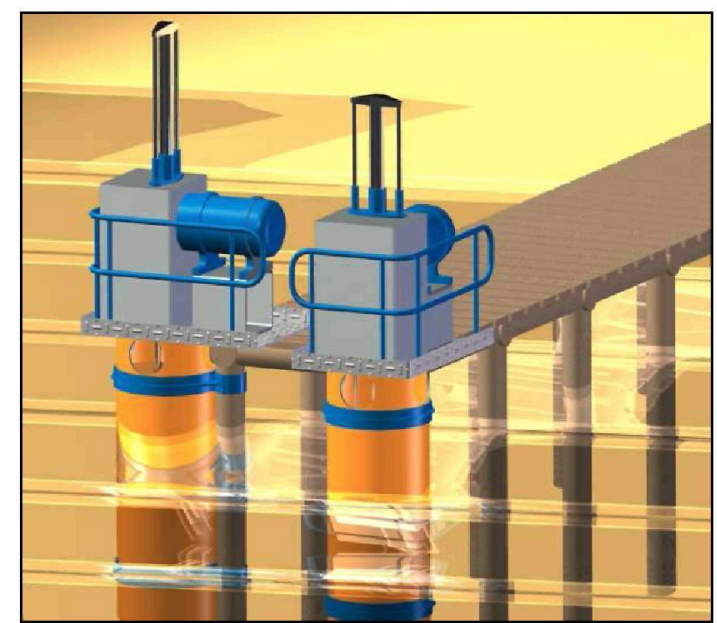

Figure 7: Shore-based 25kW Aegir Dynamo systems

Should a power output in excess of $45 \mathrm{~kW}$ be required, the design can easily be modified to allow an "array" of multiple devices coupled together. The device is highly efficient and will produce useable energy in conditions of only $300 \mathrm{~mm}$ of wave height. As can be seen from Figure 8 , each device will pay for itself 2.5 times over the course of its lifetime, produces more power than a wind generator and requires no fuel. The design of the Aegir Dynamo is versatile enough to be affixed to any stable structure at sea. Examples of this would be an oil/gas rig platform leg to provide reliable power in place of gas turbines, or the base of an offshore wind turbine to increase efficiency in the event of the unavailability of wind ( $30 \%$ compared to $80 \%$ in waves). 


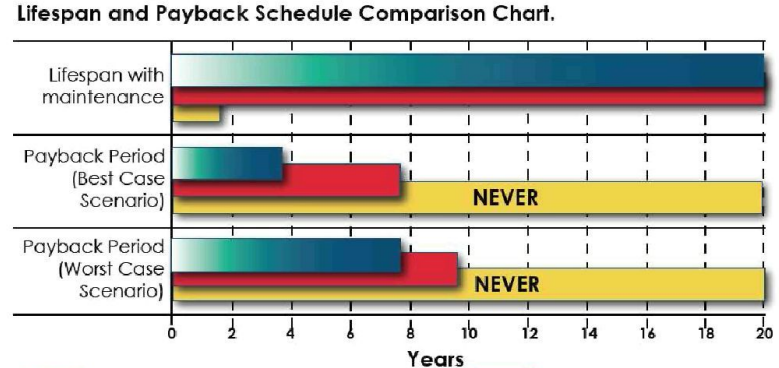

$25 \mathrm{~kW}$ Shore Based Aigir Dynamo $24 \mathrm{~kW}$ Diesel Generator

Figure 8: Lifespan and payback period comparison chart.

\section{THE DESIGN AND TESTING PROCESS}

In order to design a mechanical energy conversion device for waves, a computer aided design process is used to develop a system that would withstand the tough ocean environment that it would inevitably have to endure. The completed draft design was then subjected to finite element analysis and re-modelled and animated in 3D. Figure 9 presents a schematic diagram of the Wave energy converter (WEC) concept.

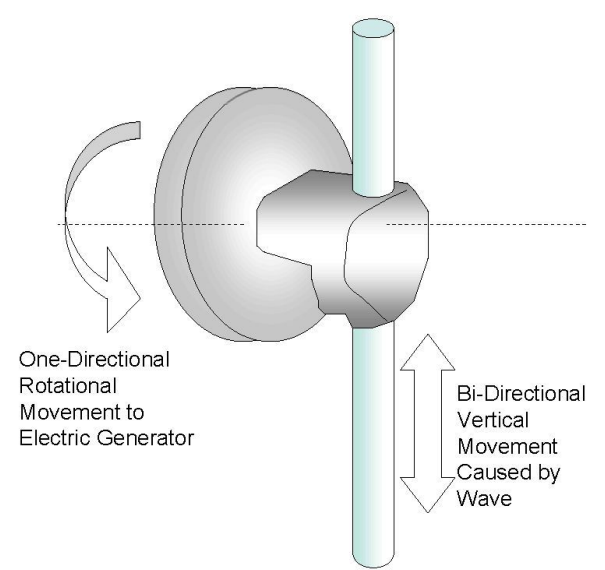

Figure 9: Schematic Description of Wave Energy Converter (WEC).

Ocean Navitas Ltd has now successfully manufactured a $45 \mathrm{~kW}$ working bench test model of the Aegir Dynamo to prove the concept, and to confirm the accuracy of the computer models. The Aegir Dynamo is a geared system that converts both the upward motion of the waves and the downward motion of gravity into singular direction rotational energy at an efficiency of $96.5 \%$. This rotational energy is then transferred to a standard permanent magnet alternator as developed for the wind turbine energy. The complete design and manufacture of the gearing system and electric generator including the casing is shown in Figure 10.

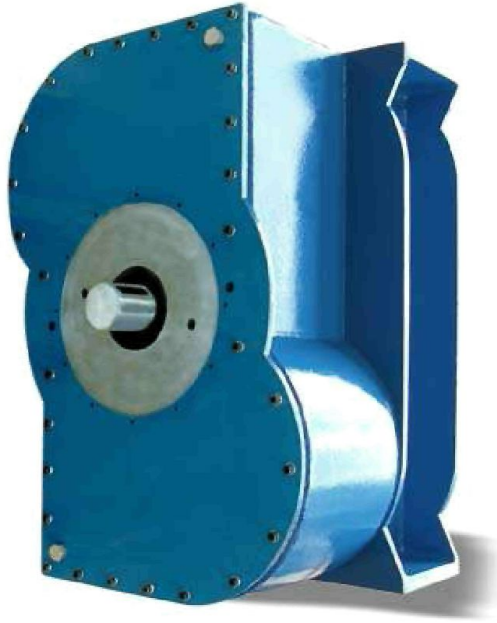

Figure 10: The complete design and manufacture of the gearing and the electrical generator.

\section{EXPERIMENTAL EVALUATION}

The design of the Wave Energy Converter (WEC) addresses the problems of efficiency, survivability, simplicity both in manufacture and maintenance. The WEC functions by taking bidirectional linear energy and turning it in to single direction rotational energy. Incorporated within the WEC is a step up in the gear ratio which increases the rotational speed of the alternator.

\subsection{Capturing Movement of Ocean's Wave}

In order to evaluate the efficiency and expected power generation of the system prior to shore-based installation, it is essential to simulate the generated power using data from real wave motion. To achieve this, an ultrasonic technology is designed and implemented to measure wave height and period, tidal range and water level. It measures the distance between its sensor and the water surface at frequency of $5 \mathrm{~Hz}$ and transmits the data via GPRS or radio to any PC loaded with Ocean Navitas Wave Analyser software. Using this information, it is possible to accurately calculate how much electrical energy will be produced by an Aegir Dynamo at any location. Data can be viewed live, or produced in report form for specific data ranges. Figure 11 presents the wave motion monitoring system. 


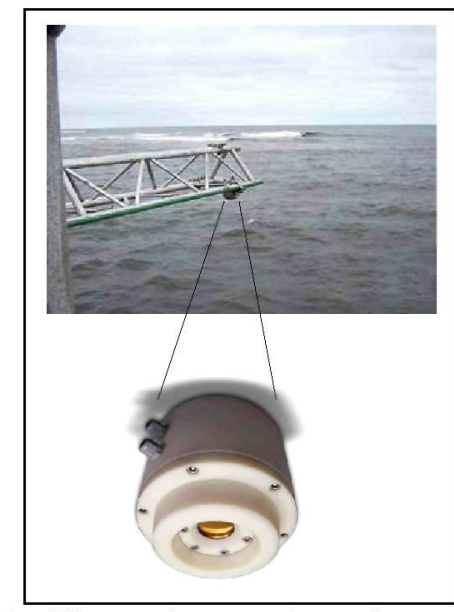

Figure 11: Ultrasonic senor is used to measure the height and time period of waves

\subsection{Hydraulic Linear Wave Simulator}

The wave movement signals captured using the ultrasonic system is utilised as input to control a hydraulic system which moves the rack of the mechanical system as shown in Figure 12. The hydraulic system was controlled by Rexroth PLC. The power generated by the three phase generator (alternator) is tested using direct connection to a bank load and to $\mathrm{ABB}$ regenerative controller that feeds electricity power to the grid.

A computer system with National Instrument PCI 6071E data acquisition card is utilised to capture the voltage, current and the position of the simulator (i.e. wave shape). The results for a $\pm 0.8 \mathrm{~m}$ wave and 10 seconds time period is shown in Figure 13. Sampling time is 1000 sample/second per channel. The frequency of current and voltage is found to be about $60 \mathrm{~Hz}$. From the data, it has been found at maximum speed the system could deliver about $25.9 \mathrm{~kW}$ using the STK500 alternator employed in the testing. The Root Mean Square (RMS) value of the power is found to be approximately $22 \mathrm{~kW}$ at optimum load.

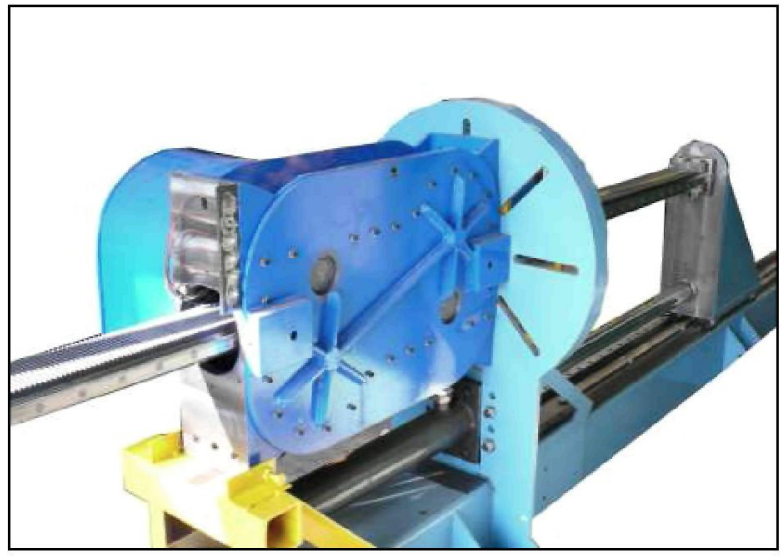

Figure 12: The developed hydraulic linear wave simulator.

Further experimental work has been done to measure forces on the system and power generated using the regenerative $\mathrm{ABB}$ controller with consistent results. The results of this experimental work will be presented in a future publication. The research team aims to have fully completed research and development by 2009, at which point an Aegir Dynamo offshore buoy will be connected to the local/national electricity grids in the Orkney Islands in Scotland or off St. Ives in Cornwall.

Figure 13: The results of using the hydraulic linear wave simulator to run the system using historical data.

Additional UK coastal installations and sites in Portugal, Spain, Thailand and the Caribbean are also under consideration/ negotiation.

\section{CONCLUSIONS}


Utilisation of renewable energy is becoming essential to sustain people's lifestyle, reduce carbon emissions of greenhouse gases and lessen the consumption of limited resources. This paper has presented an innovative technology for generating energy from waves. The paper presented description of main concepts, mechanical and electrical design, and experimental evaluation of the system. Research and results of experimental work have indicated that the technology is suitable for wide range of power generation, cost effective to manufacture and it provides a low cost per unit of electricity produced and are truly an alternative to fossil fuel.

\section{References}

[1] BBC website,

http://news.bbc.co.uk/1/hi/world/europe/7806616.stm, accessed on 10 February 2009.

[2] Eugen Rusu, C. Guedes Soares, "Numerical modeling to estimate the spatial distribution of the wave energy in the Portuguese nearshore", Renewable Energy, Volume 34, Issue 6, June 2009, Pages 1501-1516

[3] S. Srinivasa Rao, B.K. Murthy, "A new control strategy for tracking peak power in a wind or wave energy system", Renewable Energy, Volume 34, Issue 6, June 2009, Pages 1560-1566

[4] C. Boström, E. Lejerskog, M. Stålberg, K. Thorburn, M. Leijon, "Experimental results of rectification and filtration from an offshore wave energy system", Renewable Energy, Volume 34, Issue 5, May 2009, Pages 1381-1387

[5] Michelle Portman, "Involving the public in the impact assessment of offshore renewable energy facilities" Marine Policy, Volume 33, Issue 2, March 2009, Pages 332-338

[6] BBC website, http://news.bbc.co.uk/1/hi/world/americas/7359880. $\underline{\text { stm }}$, accessed on 20 January 2009.
[7] In bloom: growing algae for biofuel, BBC website, http://news.bbc.co.uk/1/hi/sci/tech/7661975.stm, accessed on 9 October 2008.

[8] R. G. Dean and R. A. Dalrymple, "Water wave mechanics for engineers and scientists", Advanced Series on Ocean Engineering, World Scientific, Singapore, 1991. ISBN 978-9810204204, PP 6465.

[9] Goda, Y. "Random Seas and Design of Maritime Structures", World Scientific, 2000.

[10] Oscillating water column wave energy converter (OWC), www.wave.net $N$ aveEnergy/Developments. htm, accessed on 10 February 2009.

[11] Pelamis Wave Power, http://www.pelamiswave.com/, accessed on 1 February 2009.

[12] BBC website, http://news.bbc.co.uk/1/hi/technology/6410839.stm, accessed on 3 March 2007.

[13] James Tedd, Jens Peter Kofoed, "Measurements of overtopping flow time series on the Wave Dragon wave energy converter", Renewable Energy, Volume 34, Issue 3, March 2009, Pages 711-717

[14] Ocean Wave Energy Company, http://www.owec.com/Inception 1.html, accessed on 10 February 2009.

[15] Wave Energy: Figueira da Foz, Portugal Finavera Renewables, http://www.finavera.com/en/wave/portugal.

[16] CETO Overview, http://www.carnegiecorp.com.au/index.php?url=/cet o/ceto-overview, accessed on 1 November 2008

[17] Buoy Parks are the Wave of the Future , www.greentribune.com/buoy-parks.htm, accessed on 11 February 2009. 